Thirty-nine (70.9\%) patients wished to extend W-TENS treatment for 3 additional months. Only one patient discontinued this additional period and results obtained at $\mathrm{M} 3$ remained stable at $\mathrm{M} 6$

Conclusion: In this study, W-TENS was more effective and better tolerated than WO in the treatment of nociceptive KOA chronic pain and should represent an interesting non-pharmacological alternative to WO.

Acknowledgements: We gratefully thank P. Fardellone (Amiens), E. Coudeyre (Clermont-Ferrand), Y. Donazzolo (Gieres), A. Amouzougan (SaintEtienne), L. Grange (Grenoble), T. Conrozier (Belfort), E. Senbel (Marseille), J.P. Sanchez (Billere), R. Forestier (Aix-les-Bains), H. Bard (Paris) and E. Gibert (Ivry-sur-Seine) for their active contribution throughout arthroTENS study

Disclosure of Interests: Emmanuel Maheu Speakers bureau: TRB chemedica, Consultant of: SUBLIMED, Moirans, FRANCE; Sandrine Soriot-Thomas Speakers bureau: Grunenthal, Consultant of: SUBLIMED, Moirans, FRANCE; Grunenthal

Kyowa Kirin pharma, Grant/research support from: Grunenthal Sanofi

Teva

Mylan

Therable, Eric Noel Consultant of: SUBLIMED, Moirans, FRANCE; Eric Lespessailles Consultant of: SUBLIMED, Moirans, FRANCE; Bernard Cortet Consultant of: SUBLIMED, Moirans, FRANCE;

DOI: 10.1136/annrheumdis-2021-eular.2086

\section{POS0280 $\quad$ ASSOCIATION OF COMPLEMENTARY AND ALTERNATIVE MEDICINE USE WITH KNEE SYMPTOMS AND KNEE STRUCTURAL CHANGES OVER 2.6 YEARS: A POPULATION-BASED COHORT STUDY OF TASMANIAN OLDER ADULTS}

Z. Wang ${ }^{1}$, G. Jones ${ }^{1}$, D. Aitken ${ }^{1}$, S. Balogun ${ }^{2}$, Z. Zhou ${ }^{1}$, L. Blizzard ${ }^{1}$, F. Cicuttini ${ }^{3}$, B. Antony ${ }^{1}$ on behalf of Musculoskeletal group. ${ }^{1}$ Menzies Institute for Medical Research, University of Tasmania, Hobart, Australia; ${ }^{2}$ College of Health \& Medicine, Australian National University, Canberra, Australia; ${ }^{3}$ Department of Epidemiology and Preventive Medicine, Monash University, Melbourne, Australia

Background: There is increasing use of complementary and alternative medicines (CAMs) alone or as an adjuvant therapy to conventional palliative medicines. ${ }^{1}$ However, there remains clinical uncertainty about the benefit of CAMs in the management of osteoarthritis in older population.

Objectives: To describe the association between CAM use (alone or in combination with conventional analgesics) with knee symptoms and structural changes amongst a representative sample of Tasmanian older adults.

Methods: A total of 1,099 participants were selected from the Tasmania Older Adult Cohort Study (TASOAC), an ongoing prospective population-based study. Exposure to CAM and conventional medications was classified into four categories according to the national drug code directory: ${ }^{2}$ CAM only, conventional analgesics only, both CAM and conventional analgesics, and neither CAMs nor conventional analgesics. Knee pain was assessed using the Western Ontario and McMaster Universities Osteoarthritis Index (WOMAC), and a 1.5-T MRI of the right knee was performed at baseline and follow-up (around 2.6 years). Longitudinal associations were assessed using mixed effect linear models.

Results: At baseline, participants' mean age was $63,86.5 \% \quad(n=951)$ reported any medication use. The prevalence of CAM use was $35.0 \%$ and of conventional analgesics was $58.6 \%$. Over follow-up, the analgesic only group had a significant increase in WOMAC pain, function, and stiffness scores compared to those who took neither CAMs nor conventional analgesics. There was a statistically significant femoral cartilage volume loss across all four groups, and no statistical difference was found between participants who takes both CAMs and analgesics group and the reference group, but participant in the CAM only or the analgesics only groups loss statistically significant more femoral cartilage volume than the reference group (Table 1)

Conclusion: CAM use alone or in combination with conventional analgesics may associate with slower progression of knee pain. Conclusive evidence on the longitudinal benefits of CAM in the management of osteoarthritis among older adults warrants more studies.

\section{REFERENCES:}

[1] Steel A, McIntyre E, Harnett J, et al. Complementary medicine use in the Australian population: Results of a nationally-representative cross-sectional survey. Sci Rep 2018;8:17325.

[2] National Center for Health Statistics. Long-term Care Drug Database System: Drugs by NDC Class Code, Drug Code and Name 2007 Available from https://www.cdc.gov/nchs/data/nnhsd/DrugsbyNDCClass3.pdf [accessed date: 202023 December].

Table 1. Association of change in clinical knee symptoms and knee structural changes over 2.6 years with different medications groups.

\begin{tabular}{|c|c|c|c|c|c|}
\hline & \multirow[b]{2}{*}{$\begin{array}{l}\text { Mean change for } \\
\text { reference group* }\end{array}$} & \multicolumn{4}{|c|}{$\begin{array}{l}\text { Change for each category, coefficient } \\
\text { (95\% confident intervals) }\end{array}$} \\
\hline & & CAMs & Both & Analgesics & $\begin{array}{l}\text { Reference } \\
\text { group* }^{\star}\end{array}$ \\
\hline No. of participants & 327 & 128 & 257 & 387 & 327 \\
\hline $\begin{array}{l}\text { WOMAC } \\
\text { pain }(5-50)\end{array}$ & $\begin{array}{c}-0.95 \\
(-1.42,-0.48)\end{array}$ & $\begin{array}{c}0.04 \\
(-0.85,0.93)\end{array}$ & $\begin{array}{c}0.32 \\
(-0.4,1.04)\end{array}$ & $\begin{array}{c}0.78 \\
(0.13,1.43)\end{array}$ & Ref \\
\hline $\begin{array}{l}\text { WOMAC function } \\
\qquad(17-170)\end{array}$ & $\begin{array}{c}-3.09 \\
(-4.52,-1.67)\end{array}$ & $\begin{array}{c}1.02 \\
(-1.7,3.73)\end{array}$ & $\begin{array}{c}1.39 \\
(-0.81,3.59)\end{array}$ & $\begin{array}{c}2.32 \\
(0.33,4.31)\end{array}$ & Ref \\
\hline $\begin{array}{l}\text { WOMAC stiffness } \\
(2-20)\end{array}$ & $\begin{array}{c}-0.39 \\
(-0.62,-0.17)\end{array}$ & $\begin{array}{c}0.15 \\
(-0.28,0.58)\end{array}$ & $0.35(0,0.7)$ & $\begin{array}{c}0.40 \\
(0.09,0.72)\end{array}$ & Ref \\
\hline $\begin{array}{l}\text { Femoral cartilage } \\
\text { volume }(\mathrm{mL})\end{array}$ & $\begin{array}{c}-187.98 \\
(-228.79,-147.18)\end{array}$ & $\begin{array}{c}-113.81 \\
(-192.60,-35.03)\end{array}$ & $\begin{array}{c}-1.92 \\
(-65.00,61.17)\end{array}$ & $\begin{array}{c}-127.19 \\
(-186.31,-68.06)\end{array}$ & Ref \\
\hline
\end{tabular}

${ }^{\star}$ Reference group=participants taken neither CAMs nor conventional analgesics

The data were fitted using mixed effect linear models, which were constructed by entering baseline medication group, phase, the interaction between medication group and phase, covariates (baseline age, sex, body mass index [BMI], baseline value of outcome), the interaction between the covariates and phase random intercept, and random slope on phase (time).

Disclosure of Interests: None declared

DOI: 10.1136/annrheumdis-2021-eular.2762

\section{POS0281 RUBUS IDAEUS LEAF EXTRACT IMPROVES SYMPTOMS IN KNEE OSTEOARTHRITIS PATIENTS: RESULTS FROM A DOUBLE BLIND RANDOMIZED CLINICAL STUDY}

Y. Henrotin $^{1}$, R. Le Cozannet ${ }^{2}$, P. Franca-Berthon ${ }^{2}$, R. Truillet ${ }^{3}$, M. Cohen Solal ${ }^{4}$ ${ }^{1}$ University of Liège, Musculoskeletal Innovative Research Lab, Liège, Belgium; ${ }^{2}$ Naturex SA, Taste \& Wellbeing, Avignon, France; ${ }^{3}$ Atlanstat, Biostatistics, Rezé, France; ${ }^{4}$ Université de Paris, Rheumatology, Paris, France

Background: Osteoarthritis (OA) is the most common cause of disability in older adults. Currently, the aim of the patient management is to reduce symptoms and to improve quality of life using therapeutic modalities with no adverse effects (1). Unfortunately, the first line treatments of OA symptoms remain nonsteroidal anti-inflammatory drugs (NSAIDS) and paracetamol which if long-term administration are associated with severe adverse effects. Therefore, we need of save alternative to manage chronic OA symptoms. One candidate is Rubus idaeus (raspberry) leaf extract rich in flavonoids and phenols known to inhibit inflammatory responses.

Objectives: The aim of this study was to investigate the effects of a 12-weeks intervention with an ethanolic extract from Rubus idaeus leaf on symptoms of knee OA. Methods: The study was a randomized, double-blind, placebo-controlled, monocentric trial of 198 subjects with femoro-tibial OA. Subjects were randomized equally to receive one daily treatment during 3 months either of 1 cap of Rubus idaeus leaf extract $400 \mathrm{mg}$, or $200 \mathrm{mg}$ or placebo (maltodextrine). The main objective of this first exploratory study was to assess pain reduction over time. Pain was measured using different scales from the Western Ontario McMaster osteoarthritis index (WOMAC) to the knee pain VAS.

Results: In the ITT population, Rubus idaeus leaf extract $400 \mathrm{mg}$ and $200 \mathrm{mg}$ after 12 weeks of treatment reduced pain measured by the VAS respectively of -10.93 (1.95) $\mathrm{mm}$ and -8.51 (1.92) $\mathrm{mm}$ compared to baseline, while placebo group had a -3.84 (1.89) $\mathrm{mm}$ reduction. The mean pain decrease induced by Rubus ideaus leaf extract was over $-7 \mathrm{~mm}$ which is clinically relevant, and reached clinically statistical difference compared to placebo with the highest dose $(p=0.017 ; 95 \% \mathrm{Cl},-13.11$ to -1.07 ). Interestingly, subgroup analysis on the participants with a $\mathrm{BMl}>25$, highlighted clinically relevant pain reduction for the 400 and $200 \mathrm{mg}$ doses compared to baseline of respectively $-13.36(2.26) \mathrm{mm}$ and $-11.25(2.14) \mathrm{mm}$ (placebo $=-0.37$ 
(2.16) $\mathrm{mm})$. The reduction was statistically different versus placebo for both doses (400 mg p < $0.0001 ; 95 \% \mathrm{Cl},(-19.95$ to -6.04$)$ and $200 \mathrm{mg} \mathrm{p}=0.0008 ; 95 \% \mathrm{Cl},(-17.64$ to -4.12$)$. There was no effect on the WOMAC subscale of pain.

Conclusion: Rubus idaeus leaf extract, even at the low dose of $200 \mathrm{mg}$, was effective to relieve pain at short-term in-patient with knee OA. As Rubus idaeus leaf extract is well tolerated, it could be an alternative to nonsteroidal anti-inflammatory drugs and paracetamol to relieve knee joint pain in OA patients. REFERENCES:

[1]Bannuru RR, Osani MC, Vaysbrot EE, Arden NK, Bennell K, Bierma-Zeinstra SMA, Kraus VB, Lohmander LS, Abbott JH, Bhandari M, Blanco FJ, Espinosa R, Haugen IK, Lin J, Mandl LA, Moilanen E, Nakamura N, Snyder-Mackler L, Trojian T, Underwood $\mathrm{M}$, McAlindon TE. OARSI guidelines for the non-surgical management of knee, hip, and polyarticular osteoarthritis. Osteoarthritis Cartilage. 2019 Nov;27(11):1578-1589. Disclosure of Interests: Yves Henrotin Speakers bureau: Expanscience, Nestlé, Tilman, Consultant of: Naturex SA, Artialis SA, Tilman SA, Seigakaku, Stemmatters, Expanscience, Romain Le Cozannet Employee of: Naturex SA, Pascale Franca-Berthon Employee of: Naturex SA, Romain Truillet Employee of: Atlanstat, Martine Cohen Solal: None declared

DOI: 10.1136/annrheumdis-2021-eular.1493

\section{POS0282 1 EVALUATION OF A NEW HYALURONATE FORMULATION ONE YEAR AFTER SINGLE INJECTION TO PATIENTS WITH SYMPTOMATIC KNEE OSTEOARTHRITIS (SOYA STUDY)}

C. Gavín ${ }^{1}$, F. Moreno ${ }^{1}$, F. J. Blanco ${ }^{2}$, J. L. Pablos ${ }^{3}$, M. A. Caracuel-Ruiz ${ }^{4}$, J. Rosas ${ }^{5}$, P. Hernández-Esteban ${ }^{6}$, F. Navarro ${ }^{7}$, P. Coronel ${ }^{8}$, M. Gimeno ${ }^{9}$ on behalf of SOYA study group. ${ }^{1}$ H.U. Fundación Alcorcón, Traumatology, Alcorcón (Madrid), Spain; ${ }^{2}$ C.H.U. a Coruña, Rheumatology, A Coruña, Spain; ${ }^{3}$ H.U. 12 de Octubre, Rheumatology, Madrid, Spain; ${ }^{4}$ H.U. Reina Sofía, Rheumatology, Córdoba, Spain ${ }^{5}$ H. Marina Baixa, Rheumatology, Villajoyosa (Alicante), Spain; ${ }^{6}$ H.U. La Paz, Traumatology, Madrid, Spain; ${ }^{7}$ H.G.U. de Elche, Rheumatology, Elche (Alicante), Spain; ${ }^{8}$ Meiji Pharma Spain, S.A., D. International, Alcalá de Henares (Madrid), Spain; ${ }^{9}$ Meiji Pharma Spain, Clinical Development, Alcala de Henares, Spain

Background: Osteoarthritis $(\mathrm{OA})$ is a leading cause of chronic pain and disability, and its prevalence is expected to increase worldwide (1) being the knee the most affected joint, especially in older adults. Intra-articular hyaluronic acid (HA) could be of particular benefit in OA patients with co-morbidities, and in case of inadequate response to other pharmacological treatments (2). HA has been generally administered in cycles of 3-5 injections, however, due to the pressure on public health systems, the trend is to reduce the number of injections maintaining the duration of effects as longer as possible.

Objectives: To assess the effectiveness and safety of a new formulation of HA, up to one year after one single injection to patients in the SOYA (Symptomatic Osteoarthritis one Year Assessment) study.

Methods: Patients with Kellgren-Lawrence $(\mathrm{KL})$ grade 2-3 and Visual Analogue Scale (VAS) pain $>=40-<80 \mathrm{~mm}$ were prospectively included to receive a single injection of MPS-HA2\%. At $6 \mathrm{~m}$ a second injection could be offered to selected patients. Primary outcome was reduction of VAS pain in the target knee. VAS for joint pain and WOMAC were recorded at 6 and 12m; Minimally Clinical Important Improvement MCII ( $>=20 \%$ relative change for VAS pain) and patient and investigator assessments (PGA, IGA) (Likert scale 0-4 points) were also estimated. Adverse events were recorded for safety assessment.

Results: One hundred and one patients (mean age 68 years, $74 \%$ female and $78 \%$ with overweight) were included. Mean pain at baseline in the target knee was $63.57 \mathrm{~mm}$ and $57 \%$ were grade $3 \mathrm{KL}$ with a mean evolution of 7.5 years. Table 1 shows the improvement in VAS and WOMAC scores at 6 and 12 months in the mITT population. Similar results were obtained in PP population.

Table 1. Changes in VAS and WOMAC scores, expressed as mean values

\begin{tabular}{lccccc}
\hline SCORE & Baseline & \multicolumn{3}{c}{6 months } & \multicolumn{1}{c}{12 months } \\
\cline { 2 - 6 } & value & value & $\begin{array}{c}\% \text { variation } \\
(95 \% \mathrm{Cl})\end{array}$ & value & $\begin{array}{c}\% \text { variation } \\
(95 \% \mathrm{Cl})\end{array}$ \\
\hline $\begin{array}{l}\text { VAS pain } \\
\text { WOMAC }\end{array}$ & 63.57 & 37.59 & $-39.74^{\star}(-49.23 ;-30.25)$ & 38.37 & $-37.67^{\star}(-47.82 ;-27.52)$ \\
total & 50.19 & 31.88 & $-37.96^{\star}(-46.83 ;-29.09)$ & 31.65 & $-36.47^{\star}(-46.20 ;-26.73)$ \\
pain & 49.37 & 32.01 & $-32.92^{*}(-43.37 ;-22.46)$ & 31.08 & $-32.07^{\star}(-43.19 ;-20.95)$ \\
stiffness & 49.12 & 28.35 & $-35.24^{\star \star}(-53.22 ;-17.23)$ & 28.71 & $-34.08^{\star}(-49.30 ; 18.86)$ \\
function & 52.07 & 35.30 & $-33.95^{\star}(-43.49 ;-24.40)$ & 35.15 & $-32.71^{\star}(-42.80 ;-22.62)$
\end{tabular}

${ }^{*}$ p-value: $0.0001 ;{ }^{* *}$-value: 0.0002 . Student test

The MCll was achieved by $66.3 \%$ of patients at $6 \mathrm{~m}$ and $62.2 \%$ at $12 \mathrm{~m}$. Regarding PGA mean score was 2.44 at baseline, 1.35 at $6 \mathrm{~m}$ and 1.46 at $12 \mathrm{~m}$ (Wilcoxon, $\mathrm{p}$-value $<0.05)$. As for the IGA mean score was 2.29 at baseline, 1.06 at $6 \mathrm{~m}$ and 1.48 at $12 \mathrm{~m}$ (Wilcoxon, p-value $<0.05$ ).
Fourteen patients received a second injection at $6 \mathrm{~m}$ and $50 \%$ of them achieved at $12 \mathrm{~m}$ a significant and clinically relevant improvement compared to baseline, above the $20 \%$ established for the MCII.

In total, 12 adverse events (8 patients) were reported, all of them local, non-serious, and of mild-moderate intensity.

Conclusion: Viscosupplementation with a single intra-articular injection of MPS-HA2\% has proven to be effective and well tolerated up to 12 months after treatment. The re-infiltration of the joint in appropriate cases has proven to be effective in a significant number of patients. The acceptability of the treatment by the patient was optimal.

REFERENCES:

[1] Sebbag E, Felten R, Sagez F, et al. The world-wide burden of musculoskeletal diseases: a systematic analysis of the World Health Organization Burden of Diseases Database. Ann Rheum Dis. 2019 Jun;78(6) 844-848

[2] Bruyère $\mathrm{O}$, Cooper $\mathrm{C}$, Pelletier JP, et al. An algorithm recommendation for the management of knee osteoarthritis in Europe and internationally: a report from a task force of the European Society for Clinical and Economic Aspects of Osteoporosis and Osteoarthritis (ESCEO). Semin Arthritis Rheum. 2014 Dec;44(3):253-63.

Disclosure of Interests: Carlos Gavín: None declared, Francisco Moreno: None declared, Francisco J. Blanco: None declared, José Luis Pablos: None declared, Miguel A. Caracuel-Ruiz: None declared, Jose Rosas: None declared, Pablo Hernández-Esteban: None declared, Francisco Navarro: None declared, PILAR CORONEL Employee of: Meiji Pharma Spain, S.A., Mercedes Gimeno Employee of: Employee of Meiji Pharma Spain, S.A.

DOI: 10.1136/annrheumdis-2021-eular.1037

\section{\begin{tabular}{|l|l|l|}
\hline POS0283 TREATMENT PATTERNS AND CLINICAL \\
\hline
\end{tabular} CHARACTERISTICS OF PATIENTS WITH OSTEOARTHRITIS OF THE HIP AND/OR KNEE TREATED WITH TRADITIONAL NSAIDS VS COX-2S: A REAL-WORLD STUDY OF COMMERCIALLY-INSURED PATIENTS}

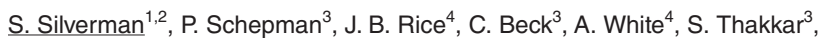
M. Johnson ${ }^{4}$, R. Robinson ${ }^{5}$, B. Emir ${ }^{3} .{ }^{1}$ Cedars Sinai Medical Center, Los Angeles, United States of America; ${ }^{2}$ David Geffen School of Medicine at UCLA, Los Angeles, United States of America; ${ }^{3}$ Pfizer, New York, United States of America; ${ }^{4}$ Analysis Group, HEOR, Boston, United States of America; ${ }^{5}$ Eli Lilly and Company, Indianapolis, United States of America

Background: The 2019 American College of Rheumatology (ACR) guidelines strongly recommend oral nonsteroidal anti-inflammatory drugs (NSAIDs) for management of hip and knee osteoarthritis $(\mathrm{OA})$ and strongly recommend topical NSAIDs for knee OA. There are, however, important safety considerations with NSAIDs in terms of increased rates of gastrointestinal, cardiovascular, and renal events. Given these risks, it is important to understand the characteristics and drug utilization of the patients who start treatment on these different treatments (i.e., traditional NSAIDs [tNSAIDs] and cyclooxygenase-2 inhibitors [COX-2s]).

Objectives: The goal of this research was to describe and compare baseline characteristics of commercially-insured patients diagnosed with $O A$ of the hip and/or knee who started treatment on different types of NSAIDs (i.e., ora tNSAIDs, topical tNSAIDs, and COX-2s).

Methods: The Optum Healthcare Solutions, Inc. claims database (1/2012$3 / 2017$ ) was used to identify patients $\geq 18$ years old, with $\geq 2$ diagnoses of hip and/or knee OA, and $\geq 90$ days supply of oral tNSAIDs, topical tNSAIDs, or COX-2s during the one-year follow up period. The index date was defined as the first prescription after the first OA diagnosis. Patients were assigned to cohorts based on the type of NSAID prescribed on index date. Patients were required to be continuously-enrolled six months before (baseline period) and 36 months after (follow-up period) the index date. Demographic and clinical characteristics including age, sex, comorbidities, and healthcare resource use (HRU) were summarized during baseline. Drug utilization characteristics including days supply and number of prescriptions for the different NSAIDs types were summarized during follow-up period.

Results: Data for 23,796 patients were analyzed: 18,100 patients received oral tNSAIDs, 4,825 received COX-2s, and 871 topical tNSAIDs. Patients who initiated treatment on oral tNSAIDs were the youngest (mean age of 60.6 vs. 64.6 for COX-2s and 65.0 for topical tNSAIDs) and topical tNSAIDs had the highest proportion of female patients ( $71 \%$ vs. $62 \%$ for oral tNSAIDs and $63 \%$ for COX-2s). The topical tNSAIDs cohort had the highest presence of chronic kidney disease $(2.6 \%$ vs. $1.0 \%$ and $1.5 \%$ for oral tNSAIDs and COX-2s, respectively) and congestive heart failure $(2.5 \%$ vs. $0.8 \%$ and $1.7 \%$ for oral tNSAIDs and COX-2s, respectively) at baseline. In terms of HRU during baseline, topical 